\title{
NORMAL AND HIGH-STRENGTH R/C DEEP BEAMS UNDER PURE TORSION AND CODES EVALUATION
}

\author{
دراسة سلوك اللمي للكعرات العمبقة من الخرساتة المسلحة العادية والعالية العقارمة وتقيرم منطلبات الكودات
}

Alimed M. Yousef

Associate Prof., Structural Eng. Department, Faculty of Eng., Mansoura University, Egypt

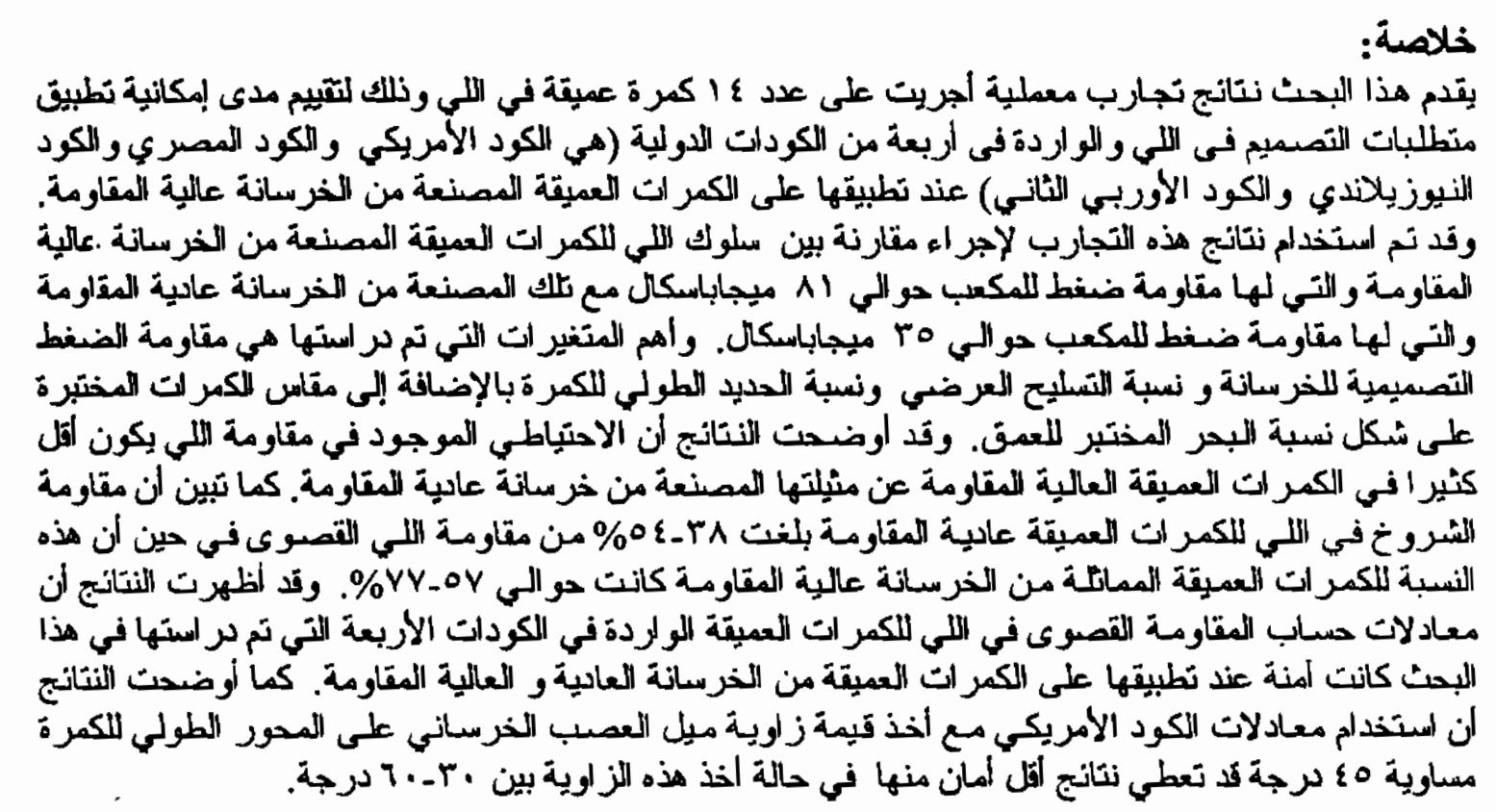
ABSTRACT

Fourteen reinforced concrete deep beams were tested under pure torsion in order to evaluate the torsion design provisions of ACI 318-02 Building Code, the Egyptian code (ECCS-2001). the New Zealand code (NZS 3101-95), and the Eurocode 2 (EC-2) when applied to HighStrength Concrete (HSC) deep beams. The results of these tests have been used to compare the torsional behavior of reinforced deep beams constructed from Normal-Strength Concrete (NSC with characteristic cube compressive strength $f_{c u}$ of about $35 \mathrm{MPa}$ ) and HSC (with $f_{c u}$ of about $81 \mathrm{MPa}$ ). The main parameters examined in this study were the design compressive strength, the provided transverse reinforcement ratio, the quantity of longitudinal and skin reinforcement and the size of the tested beans in the form of the tested span to total height ratio $(L / h=1.0,2.0$ and 3.0). The results showed that the reserve in the torsional strength of the HSC deep beams after cracking is considerably less than that of the similar NSC deep beams. The cracking torsional strength of the tested NSC deep beams is about $38-54 \%$ of the measured ultimate torsional strength, while the same ratio for the similar HSC deep beams is about $57-77 \%$ of the measured ultimate strength. The design torsional strength equations of the four international codes considered in this study were safe and conservative when applied to NSC and HSC deep beams. The predictions of the ultimate torsional strength of the deep beams according to the method of $\mathrm{ACl} 318-02$ and using a value of the angle between the concrete struts and the longitudinal axis of the beam $\theta$ equal to $45 \mathrm{deg}$ may give a conservative results less than that calculated using this angle between 30 and $60 \mathrm{deg}$.

Keywords: Deep Beams; Reinforced High-Strength Concrete; Torsion Strength; Codes. 


\section{INTRODUCTION}

For many years, concrete with compressive strength in excess of $40 \mathrm{MPa}$ was available at only a few locations. However, in recent years, the applications of High-Strength Concrete (HSC) have increased, and HSC with compressive strength approaching 140 $\mathrm{MPa}$, has now been used in many parts of the world [1]. The growth has been possible as a result of recent developments in material technology. The main advantage of using HSC is the cost saving from the use of lower volumes of concrete which results in reduced shuttering costs and lighter foundations [1].

Deep beams are characterized by relatively small values of span to depth ratios. Bccausc of thcir proportions, they develop mechanism of force transfer quite different lirom that in shallow beams. Until now, there is no unified definition for the deep beams. According to the ACl-ASCE Committee 326 [2], a beam with shear span-1o-depth ratio $(a / d)$ less than 1.0 is slassified as deep beam, and a beam with $a^{\prime} d$ exceeding 2.5 as an ordinary shallow beam. Any beam in between these two limits is classified as a short beam. According to the New Zealand code for design of concrete structures (NZS 310195) [3] a simple beam with $a / d$ less than 2 is classified as deep beam. The Eurocode 2 (EC-2) [4] defines the simple beam with wtal clear span-to-depth ratio $\left(L_{n} / d\right)$ less than 2 as deep beam. Deep beams in ACI 318 building code $(\mathrm{ACl} 318-02)$ [5] refer to beans with $\left(L_{1} / d\right)$ ratio less than 5.0 . According to the Egyptian code for design of concrete structures (ECCS-2001) [6] a simple beam with effective span to depth ratio less than 1.25 is considered as a deep beam. For the analysis and design of shallow and deep reinforced NSC beams, most of the available codes adopted the rational thin-walled tube space truss model [3-6]. Recently, Rahal and Collins [7] tested four beams constructed from NSC to evaluate the torsion design procedures of $\mathrm{ACl}$ 318-02 and AASHTO-LRFD. The only reported study on the torsional behavior of HSC deep beams has been published by Ashour et al. [8]. The studied parameters were the concrete eompressive strength and the span-to-depth ratio.

The main objective of this paper is to examine the applicability of the torsion design provisions of the $\mathrm{ACl} 318-02$ building code, ECCS-2001, NZS 3101-95 and EC-2 when applied to HSC deep beams. The results of these tests have been used to compare the torsional behavior of reinforced NSC and HSC deep beams.

\section{CRACKING AND ULTIMATE TORSIONAL STRENGTH OF R/C DEEP BEAMS ACCORDING TO THE CODES PROVISIONS}

\subsection{Cracking Torsional Strength}

For calculating the cracking torsional monent $T_{c r}$, the NZS 3101-95, ACl 318-02 Building Code and ECCS-2001 use the following equation:

$T_{c r}=0.33\left(\frac{A_{c p}^{2}}{P_{c p}}\right) \sqrt{f_{c}}$

where $A_{c p}$ is the gross area bounded by outer perimeter of concrete cross-section, $p_{c p}$ is the outer perimeter of concrete cross-section and $f_{c}$ is the design cylinder compressive strength. The EC-2 does not give an equation for calculating the cracking torsional strength.

\subsection{Ultimate Torsional Strength}

\section{ACI 318-02}

The nominal torsional stress, $v_{t n}$, can be calculated from the following equation:

$v_{m}=\frac{T_{n}}{2 A_{o} t_{e}}$

where $T_{n}$ is the nominal torsional moment, $t_{e}$ is the wall thickness of the equivalent thin-walled tube at the point where the shear stress, $v_{t}$, due to torsion is 
being computed; $A_{o}$ is the cross-sectional area bounded by the centerline of the shear flow. The area $A_{o}$ is empirically taken as 0.85 times the area $A_{\text {oh }}$ enclosed by the outermost closed stirrups in the section, and $l_{e}$ is taken as $\left(A_{o h} / p_{h}\right)$ where $p_{h}$ is the perimeter of the centerline of the closed stirrups. The uitimate torsional moment $T_{\text {u }}$ usually taken less than or equal to $\left(\varphi T_{n}\right)$, where $\varphi$ is the strength reduction factor.

If the ultimate shear stress, $v_{t u}$, induced by torsion as calculated from Eq. (1) is less than a minimal value $v_{\text {tnMIN }}$, the torsional effects may be neglected. The maximum ultimate torsional shear stresses $v_{\operatorname{In} M A X}$ are limited also by the $\mathrm{ACl}$ 318-02 regardiess of the amount of reinforcement to safeguard against wide cracks and large deformations. The minimum and maximum values of $v_{t u}$ allowed by the code arc given in the form of a ratio of square root of the design cylinder compressive strength of concrete as follows:

$v_{\text {hIIIN }}=0.08 \sqrt{f_{c}^{\circ}} \mathrm{MPa}$

$v_{\text {mMAX }}=0.66 \sqrt{f_{c}} \quad \mathrm{MPa}$

If the ulcimate shear stress induced by torsion is greater than the minimum value and less than the maximum value given by Eq. (4), reinforcement for torsion must be provided. The torsional reinforcement must consist of closely spaced well-anchored stirrups and of additional longitudinal bars. The following equations are used:

$A_{i}=\frac{T_{n} \cdot s}{2 A_{o} f_{y v} \cot \theta}$

$A_{l}=\frac{T_{n} p_{h}}{2 A_{o} f_{y l}} \cot \theta$

$\cot \theta=\sqrt{\frac{A_{l} f_{y l} s}{A_{t} f_{y v} p_{h}}}$

where $A_{t}$ is the area of one stirrup leg, $f_{y v}$ is the yield stress of stimup's steel not to exceed $400 \mathrm{MPa}, s$ is the spacing between stirrups, $\theta$ is the angle between the concrete struts and the longitudinal axis of the beam and shall not be taken smaller than $30 \mathrm{deg}$ nor larger than $60 \mathrm{deg}, A_{l}$ is the area of the required additional longitudinal reinforcement and $f_{y l}$ is the yield stress of the longitudinal bars. According to this code, the angle $\theta$ can be taken equal $45 \mathrm{deg}$ for nonprestressed members. For convenience in design, $A_{l}$, can be expressed in terms of the area of the torsional stirrups:

$A_{l}=\frac{A_{l} f_{y v} p_{h}}{s f_{y l}} \cot ^{2} \theta$

The minimum area of one leg of stirrup for torsion is given as follows:

$A_{t}=\frac{0.17 s . b}{f_{y v}}$

where $b$ is the breadth of the beam crosssection. The spacing between the transverse torsion reinforcement shall not exceed the smaller of $300 \mathrm{~mm}$ or $\left(P_{h} / 8\right)$. The minimum longitudinal reinforcement should be ealculated from the following expression:

$$
A_{s / \min }=\left(\frac{0.4 I A_{c p} \sqrt{f_{c}}}{f_{y l}}\right)-
$$

The longitudinal reinforcement required for torsion shall be distributed around the perimeter of the closed stirrups with a maximum spacing of $300 \mathrm{~mm}$. There shall be at least one longitudinal bar in each corner of the stirrups. The minimum diameter of the additional longitudinal bars shall be $10 \mathrm{~mm}$ or $1 / 15$ of the spacing between stimups whichever is larger.

\section{ECCS-2001}

The torsional provisions of reinforced concrete beans in this code is almost the same as that in ACI 318-02. However, some differences are found as will be shown next. The ultimate torsional shear stress, $v_{t u}$, due to ultimate torsional 
moment $T_{u}$ is given by an equation similar to Eq. (2). The minimum and the maximum values of $v_{t u}$ are given as follows:

$$
\begin{aligned}
& v_{t u M I N}=0.06 \sqrt{\frac{f_{c u}}{\gamma_{c}}} \\
& v_{t u M A T X}=0.70 \sqrt{\frac{f_{c u}}{\gamma_{c}}}
\end{aligned}
$$

where $\gamma_{c}$ is the partial safety factor for concrete which is taken equal to 1.5.

The ECCS-2001 assumes that for reinforced concrete members the angle $\theta$ is $45 \mathrm{deg}$ throughout. Equations 5 and 6 are modified as follow:

$A_{1}=\frac{T_{u} \cdot s}{2 A_{o}\left(f_{y v} / \gamma_{s}\right)}$

$A_{l}=\frac{T_{u} p_{h}}{2 A_{o}\left(f_{y l} / \gamma_{s}\right)}$

where $\gamma_{s}$ is the partial safety factor for reinlorcement steel which is taken equal to 1.15 .

The minimum closed stirrup reinforcement for torsion and the minimum longitudinal torsion reinforcement is approximately the same as that given in the ACI 318-02 (Eq. 9 and Eq. 10). The spacing $s$ shall not exceed the smaller of $200 \mathrm{~mm}$ or $\left(P_{h} / 8\right)$. The diameter of the longitudinal bars should not be less than $12 \mathrm{~mm}$ or $(s / 15)$ whichever is larger.

\section{NZS 3101-95}

The nominal torsional stress, $v_{t n}$, can be calculated from the following equation:

$v_{t n}:=\frac{T_{n}}{2 A_{o c} t_{o c}}$ where $t_{o c}$ is the wall thickness of the equivalent thin-walled tube and $A_{\alpha c}$ is the cross-sectional area enclosed by the line connecting the centers of longitudinal bars in the corners of the stirrups. The value of $t_{o c}$ is taken as $\left(0.75 A_{o c} p_{o c}\right)$ where $p_{o c}$ is the perimeter of $A_{o c}$. The value of $v_{t n}$ shall not exceed $\left(0.2 f_{c}\right)$ or $6 \mathrm{MPa}$. The minimum nominal torsional stress required by this code is the same as that given in Eq. (3).

The required area of closed stirrups $A_{t}$ and the required $A_{l}$ can be calculated as follows (with $\theta$ equal to $45 \mathrm{deg}$ ):

$A_{t}=\frac{T_{n} \cdot s}{2 A_{o c} f_{y v}}$

$A_{l}=\frac{T_{n} p_{o c}}{2 A_{o c} f_{y l}}$

The minimum amount of stirrups and longitudinal bars shall be provided such that:

$$
\sqrt{\frac{A_{t}}{s} \cdot \frac{A_{1}}{p_{o c}}} \geq \frac{1.5}{f_{y v}} \cdot \frac{A_{c p} t_{c}}{A_{o c}}
$$

where $t_{c}$ shall be taken equal to $\left(0.75 A_{c p} / p_{c p}\right)$. The minimum requirements for longitudinal bars is the same as that in $\mathrm{ACI}$ 318-02. The spacing between the transverse torsion reinforcement shall not exceed the smaller of $300 \mathrm{~mm}$ or $\left(P_{o c} / 8\right)$.

\section{EC-2}

The design ultimate torsional moment $T_{u}$ should not be greater than $T_{R d l}$ and $T_{R d 2}$ where $T_{R d l}$ is the maximum torsional moment that can be resisted by the compression struts in the concrete and $T_{R d 2}$ is the maximum torsional moment that can be resisted by the stirrups. The values of $T_{R d l}$ and $T_{R d 2}$ can be calculated from the following equations: 
$T_{R d l}=T_{u c}=\frac{2 v t_{o} A_{k} f_{c d}}{(\cot \theta+\tan \theta)}$

$T_{R d 2}=T_{u t}=\frac{2 A_{k} A_{t} f_{y t} \cot \theta}{s}$

where $t_{o}$ is the equivalent thickness and should be taken less than or equal to $\left(A_{c p} / p_{c p}\right), A_{k}$ is the area enclosed within the center line of the equivalent thin-walled section and $p_{k}$ is the perimeter of the area $A_{k}$. The angle $\theta$ can be calculated using Eq. (6). The EC-2 requires that the angle $\theta$ should be taken so that

$$
|0.4| \leq \cot \theta \leq|2.5|
$$

The efficiency factor $v$ can be calculated from the following equation:

$$
v=0.7\left[0.7-\left(f_{c k} / 200\right)\right] \geq 0.35
$$

where $f_{c k}$ is the characteristie cylinder compressive strength of concrete at 28 days. The design cylinder compressive strength of concrete $f_{c d}$ is equal to $f_{c k}$ divided by $\gamma_{c}\left(\gamma_{c}\right.$ is the partial safety factor for concrete which is taken equal to 1.5).

The ultimate torsional moment depending on the torsional strength of the longitudinal bars $T_{u l}$ can be calculated as follows:

$$
T_{u l}=\frac{2 A_{o} A_{l} f_{y l}}{p_{h} \cot \theta}
$$

The spacing between the torsion stirrups shall not exceed the smaller of $200 \mathrm{~mm}$ or $\left(P_{k} / 8\right)$. The diameter of the longitudinal bars should not be less than $12 \mathrm{~mm}$ and the distance between these bars should not exceed $350 \mathrm{~mm}$. The EC-2 did not exactly define the area $A_{k}$ and the perimeter $p_{k}$. In this study, the area $A_{k}$ will be taken equal to that recommended by the ACI $318-02$ as 0.85 times the area $A_{\text {oh }}$ enclosed by the centerline of outermost closed stirrups in the section and $p_{k}$ is the perimeter of $A_{o h}$.

\section{EXPERIMENTAL PROGRAM}

\subsection{Details of the Tested Deep Beams}

The test speeimens consisted of fourteen reinforeed concrete beams with web reinforcement divided into 2 groups. The first group consists of 7 NSC deep beans and the second group consists of seven similar HSC deep beams. All the tested beams have the same rectangular erosssection of $125 \mathrm{~mm}$ wide and $450 \mathrm{~mm}$ total height. A concrete cover of $20 \mathrm{~mm}$ was used. It should be noted that, all the tested beams are classified as deep beams according to ACI 318-02 building code. The beams subjected to torsion can be classified aeeording to the provided reinforcement into the following three cases: 1) over-reinforeed, when crushing of concrete takes place before yielding of both stirrups and longitudinal bars; 2) underreinforced, when both the stirrups and the longitudinal bars yield before crushing of the concrete diagonals; 3 ) partially overreinforced, when either stirrups or longitudinal bars, but not both, yield before crushing of conerete diagonals. The torsion provisions of the studied codes are based on under-reinforced sections. Most of the tested beams can be considered torsionally under-reinforced as will be explained in the next sections. Table 1 summarizes the details of the test program, while the reinforcement arrangement and dimensions of the tested beans are shown in Fig. 1. The main parameters considered are:

1. The tested span to total height ratio $(L / h)$. Three $L / h$ ratios were tested $(L / h=1$, 2 and 3), and the tested span for the beams was equal to 450,900 and $1350 \mathrm{~mm}$. respectively.

2. Two different spacing between stirrups $(100 \mathrm{~mm}$ and $200 \mathrm{~mm})$ were tested. The diameter of the stirrups $d_{\nu}$ was the same for all the tested beams $\left(d_{v}=6 \mathrm{~mm}\right)$. The provided stirrups cover the requirements of 
was held against torsional rolation. The details of the loading arrangement are shown in the schematic illustration in Fig. 2. The clear span of the tested deep bcams was changed according to the tested $(L / h)$ ratio. Electrical strain gauges were bonded to the longitudinal torsional reinforcement, the skin reinforcement and the stirrups at some locations as shown in Fig. 1. The load was applicd with increments up to failure at a distance of $225 \mathrm{~mm}$ from the longitudinal centcrline of the tested deep beam. At each load increment, torsional rotations at the free cnd of the deep beam were recorded. The test sclup is shown from the photograph in Fig. 3.
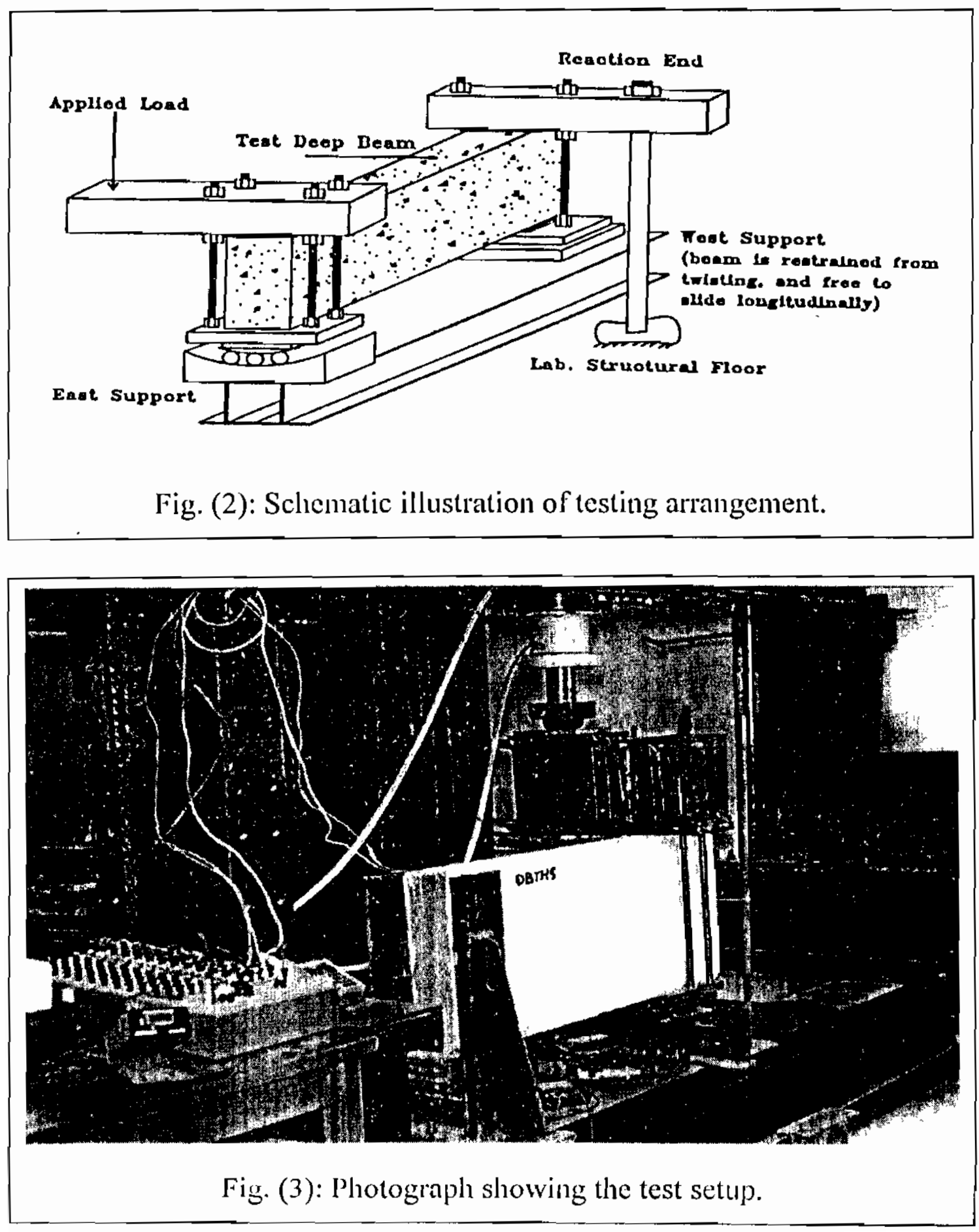


\section{ANALYSIS OF TEST RESULTS}

\subsection{Applied Torsional Moment- Strain Relationships}

The recorded strain readings in the upper longitudinal reinforcement on the middle of the tested span of the beans and in the legs of the middle stirrups for some of the tested specimens are plotted in Fig. 4 and 5 , respectively, versus the applicd torsional moment. The results of the tests indicate that, the strains in the longitudinal and in the transverse rcinforcement bcfore the initial concrete cracking were vcry small. A sudden high increase in the strains took place after the formation of the first spiral crack. Following this, the tensilc steel strains in the stirrups and the longitudinal bars increased at a faster rate up to yielding. As can bc scen from Fig. 4a, comparing the strains recorded in the transverse reinforcenent of the tested IISC and NSC deep bcams showed that increasing the concrete strength for the same reinforccment reduced considerably the strains at the same torsional moment. The strains recorded in the stirrups of decp beams DBTN2, DBTN3 and DBTN4 ivcre considerably more than that of beams DBTH2, DBTH3 and DBTH4, respectively. Yielding of the stirrup's legs in the tested HSC and NSC bcams did not have any considerable observed indication on the spiral cracks. For the similar IISC and NSC deep beans, increasing the spacing between the stirrups increases the recorded strains in the stirrups. For all the tested deep beans, yielding of the stirrujss was altained before yiclding of the longitudinal bars or crushing of the concretc. This was because in all the lested decp bcams, the provided stirrups covers, by a small percentages, the minimum requirements of the codes. For the similar HSC and NSC deep beams, increasing the $L / h$ ratio increased considerably the recorded strains in the stirrups. As can be scen from Fig. 4.b, the strains recorded in the stirrups of beam DBTH7 $(L / h=3.0)$ were considerably larger than that of the sinilar beam DBTH 2 but with $(L / h=1.0)$.

From Fig. 5a, it can be secn that the recorded strains at the same load for NSC bcams ivcre larger than the similar beanis construeted from HSC. Failure of the IISC beams was controlled by the amount of the strain in the longitudinal bars. This was obscrved especially for all the tested HSC beams regardless of the amount of stirrups. Increasing the strain in the longitudinal bars gradually increases the main spiral crack width, and at yielding of these bars the bean forms a torsional hinge at the yicld/spiral crack Iocation. For HSC beams, crushing of concrete at the torsional hinge region took place at a torsional moment gencrally larger than the torsional moment at yiclding of the longitudinal bars. For NSC specimens, crushing of the concrete may take place at high strain levels in the longitudinal bars but before yiclding of these bars as can be seen from Fig. 5b for beams DBTNI, DBTN2 and DBTN7. Increasing the $L / h$ ratio for the similar HSC and NSC deep beams, increased the recorded strains in the longitudinal comer bars.

\subsection{Cracking Belıavior and Torsional Strength}

The recorded values of the cracking and ultimate torsional moment and corresponding angle of twist are summarized in Table 2. Upon comparing the dcep beams of the same reinforccment details construeted from NSC and HSC, it is obvious that, increasing the concrete strength considerably increases the valuc of the cracking torsional moment. Before the formation of cracks, the behavior of the beams under pure torsion was initially elastic. In this case, torsion is mainly resisted by concrete. 


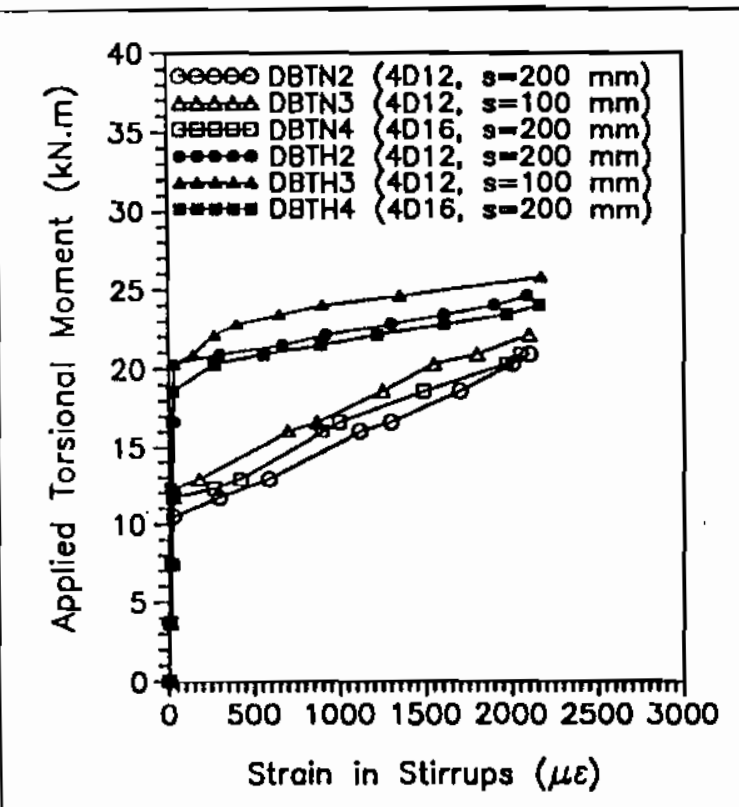

(a)

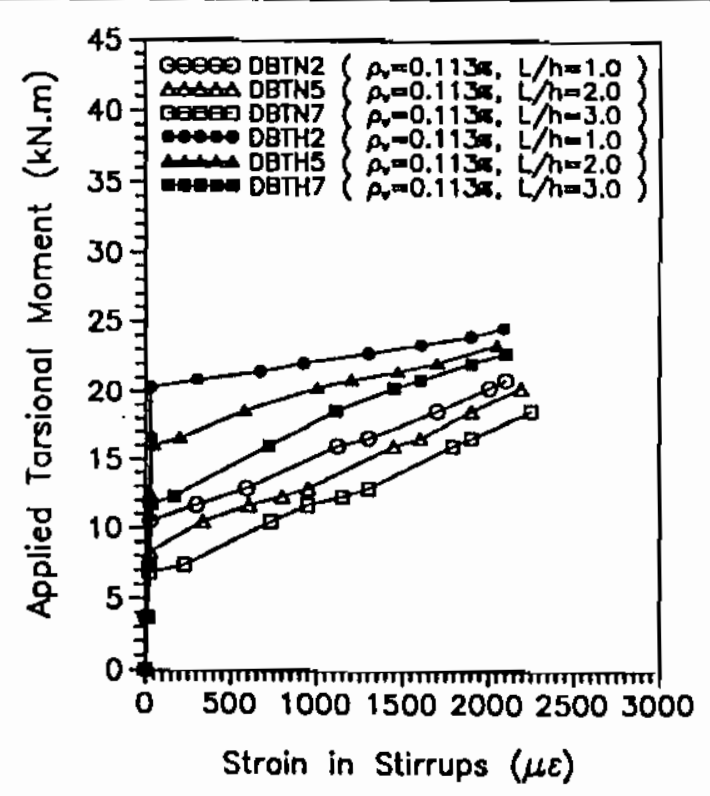

(b)

Fig. (4): Experimental torsional moment-stirrups strains relationships for the tested deep beams.

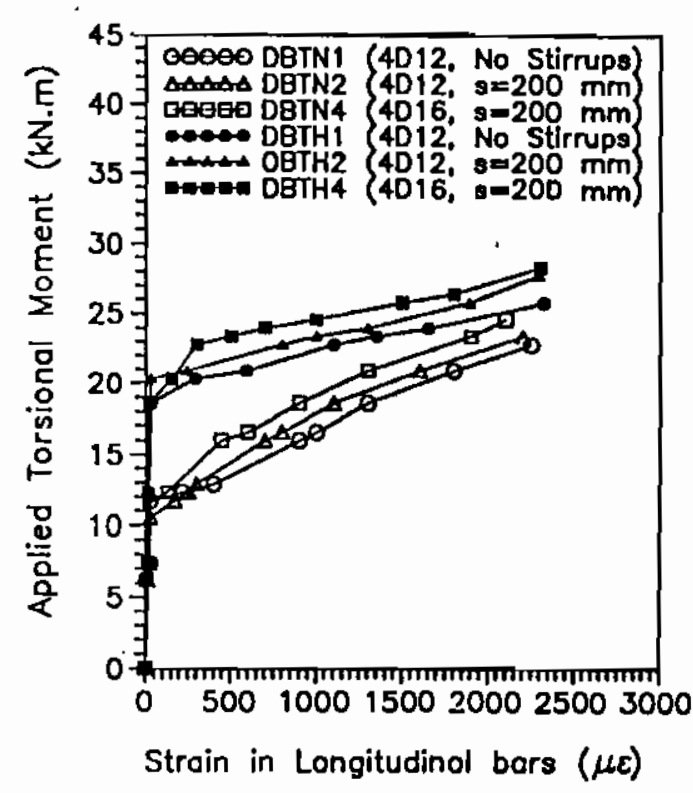

(a)

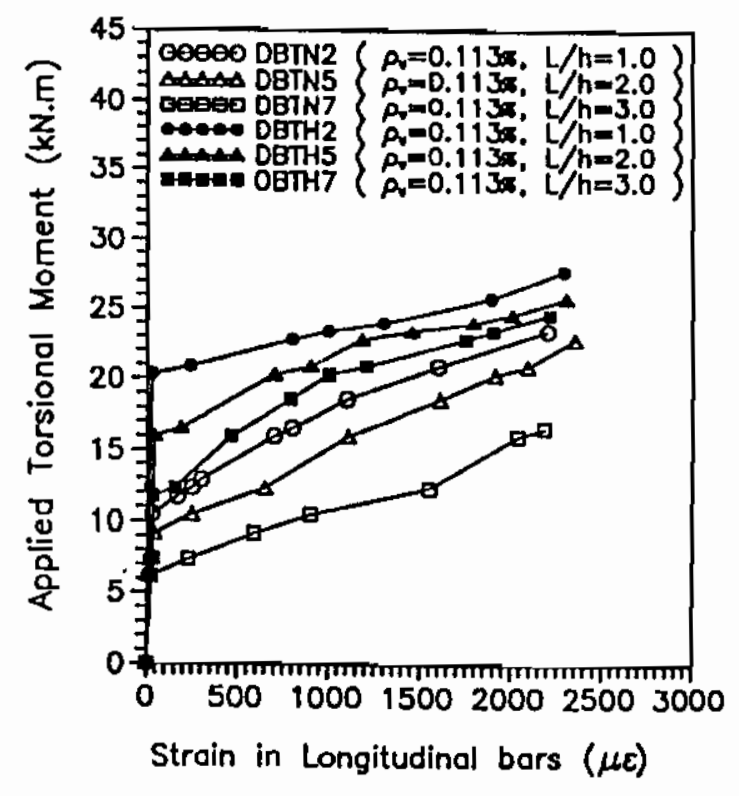

(b)

Fig. (5): Experimental torsional moment-longitudinal steel strains relationships for the tested deep beams. 
Increasing the spacing between the stirrups or the diameter of the longitudinal bars or existence of skin bars did not have a considerable effect on the cracking torsional moment. The recorded cracking torsional moments of the tested HSC deep beams were larger than that of the similar NSC beams by $58-79 \%$.

The percentages of inerease in the ultimate torsional strength were greatly less than the percentage of increase of the cracking torsional strength. The recorded ultimate torsional moment of the HSC deep beam DBTH5 was larger than that of DBTN5 by $10 \%$, while the recorded ultimate torsional moment of DBTH7 was larger than that of DBTN 7 by $25 \%$. Increasing the $L / h$ ratio reduces considerably both the cracking and ultimate torsional strength of the tested NSC and HSC deep beams. For the tested NSC beans, increasing the $L / h$ ratio from 1 to 3 (DBTN2 and DBTN7) reduced the cracking and the ultimate torsional strength by $37 \%$ and $28 \%$, respectively, while for the tested HSC deep beans, increasing the $L / h$ ratio from 1 to 3 (DBTH2 and DBTH7) reduced the cracking and the ultimate torsional strength by $41 \%$ and $22 \%$, respectively. It can be seen from Table 2 that, the cracking torsional strength of the tested NSC deep beams is about $38-54 \%$ of the measured ultimate torsional strength, while the same ratio for HSC deep beams is about $57-77 \%$ of the measured ultimate strength. This result showed that the reserve in the torsional strength of the tested HSC deep beams after cracking is relatively less than that of the similar NSC deep beams. This can be attributed to the brittle nature of the HSC. While the applied torsional moment increases, the appearance and progress of diagonal cracks up and down on the longer sides of the cross-section increases forming a spiral around the beam whieh spreads over the test regions. The spiral cracks angle with respect to the horizontal plane of the bean were between 30 to $55 \mathrm{deg}$ for all the tested beams. Photographs of the crack patterns at failure for some of the tested beams with $L / h=1$ and 2 are shown in Figs. 6 and 7, respectively. The numbers written along the cracks on the photographs indicate the torsional moment (in $\mathrm{kN} . \mathrm{m}$ ) at termination of cracks observed at the end of a particular load stage.

The crack patterns of the tested deep beams with $L / h=1$ were approximately similar, as can be seen from the photographs in Fig. 6, despite that the stirrups ratio was differen $\left(\rho_{v} \%=0.0,0.113\right.$ and 0.226$)$. This can be attributed to the tested very short span. The crack patterns of the tested HSC and NSC deep beams with $L / h=2$ and 3 were essentially based on the $L / h$ ratio and the spacing between the stirrups of the deep beams. Reducing the $L / h$ ratio and increasing the spacing between the stirrups resulted in a few number of spiral cracks for HSC and NSC deep beams as can be seen from the photographs in Fig. 7 for beam DBTH5 and DBTN5 which experienced only 2 major cracks, while beams DBTH6 and DBTN6 experienced several cracks over the tested region. The existence of the skin bars in beams DBTN4 and DBTH4 did not have observed effect on the number of the torsional craeks.

The observed failure of the tested NSC and HSC deep beams was mainly controlled by the yielding of the longitudinal reinforcement. Whereas the applied torsional moment approaches the ultimate torsional capacity of the beam (and shortly after the yielding of the longitudinal bars), the width of the main crack (not always the first one) increases very rapidly and causes the longitudinal bars to pullout from the concrete, resulting in a reduction of the value of the applied torsional moment. At the end of the test, all deformations take place at the main erack, where the rest of the bean at this stage can be considered unloaded as can be seen from the photographs in Figs. 6 and 7. 
Table (2): Summary of test results.

\begin{tabular}{|c|c|c|c|c|c|c|c|c|}
\hline \multirow{2}{*}{ Beam } & \multicolumn{2}{|c|}{ At Cracking } & \multicolumn{2}{|c|}{ At Ultimate } & \multirow{2}{*}{$\begin{array}{c}\text { Predicted Cracking } \\
\text { Torsional Strength } \\
T_{c r P R E}(E q .1) \\
k N . m\end{array}$} & \multirow{2}{*}{$\frac{T_{c r E X P}}{T_{c r P R E}}$} & \multirow{2}{*}{$\begin{array}{c}\text { Proposed Cracking } \\
\text { Torsional Strength } \\
T_{c r P R O} \\
k N . m\end{array}$} & \multirow{2}{*}{$\frac{T_{c r E X P}}{T_{c r P R O}}$} \\
\hline & $\begin{array}{c}T_{c r E X P} \\
k N . m\end{array}$ & $\begin{array}{c}\text { Twist } \\
\text { Deg } / m\end{array}$ & $\begin{array}{l}T_{u E X P} \\
k N . m\end{array}$ & $\begin{array}{c}\text { Twist } \\
\text { Deg/m }\end{array}$ & & & & \\
\hline DBTN1 & 12.30 & 0.75 & 22.80 & 8.00 & 4.92 & 2.50 & 5.97 & 2.06 \\
\hline DBTN2 & 11.70 & 1.00 & 24.00 & 9.00 & 4.92 & 2.38 & 5.97 & 1.96 \\
\hline DBTN3 & 12.90 & 1.00 & 24.60 & 8.50 & 4.92 & 2.62 & 5.97 & 2.16 \\
\hline DBTN4 & 12.30 & 1.00 & 25.80 & 9.00 & 4.92 & 2.50 & 5.97 & 2.06 \\
\hline DBTN5 & 10.50 & 1.25 & 23.40 & 7.00 & 4.92 & 2.13 & 5.97 & 1.76 \\
\hline DBTN6 & 9.20 & 1.25 & 24.00 & 7.50 & 4.92 & 1.87 & 5.97 & 1.54 \\
\hline DBTN7 & 7.40 & 1.50 & 17.20 & 6.50 & 4.92 & 1.50 & 5.97 & 1.24 \\
\hline DBTH1 & 20.30 & 1.00 & 26.40 & 8.00 & 7.66 & 2.65 & 9.28 & 2.19 \\
\hline DBTH2 & 20.90 & 1.25 & 27.70 & 8.50 & 7.66 & 2.73 & 9.28 & 2.25 \\
\hline DBTH3 & 20.90 & 1.00 & 28.30 & 7.50 & 7.66 & 2.73 & 9.28 & 2.19 \\
\hline DBTH4 & 20.30 & 1.25 & 30.10 & 8.50 & 7.66 & 2.65 & 9.28 & 2.25 \\
\hline DBTH5 & 16.60 & 1.50 & 25.80 & 9.00 & 7.66 & 2.17 & 9.28 & 1.79 \\
\hline DBTH6 & 16.00 & 1.50 & 27.10 & 9.00 & 7.66 & 2.09 & 9.28 & 1.72 \\
\hline DBTH7 & 12.30 & 1.25 & 21.50 & 8.50 & 7.66 & 1.61 & 9.28 & 1.33 \\
\hline
\end{tabular}
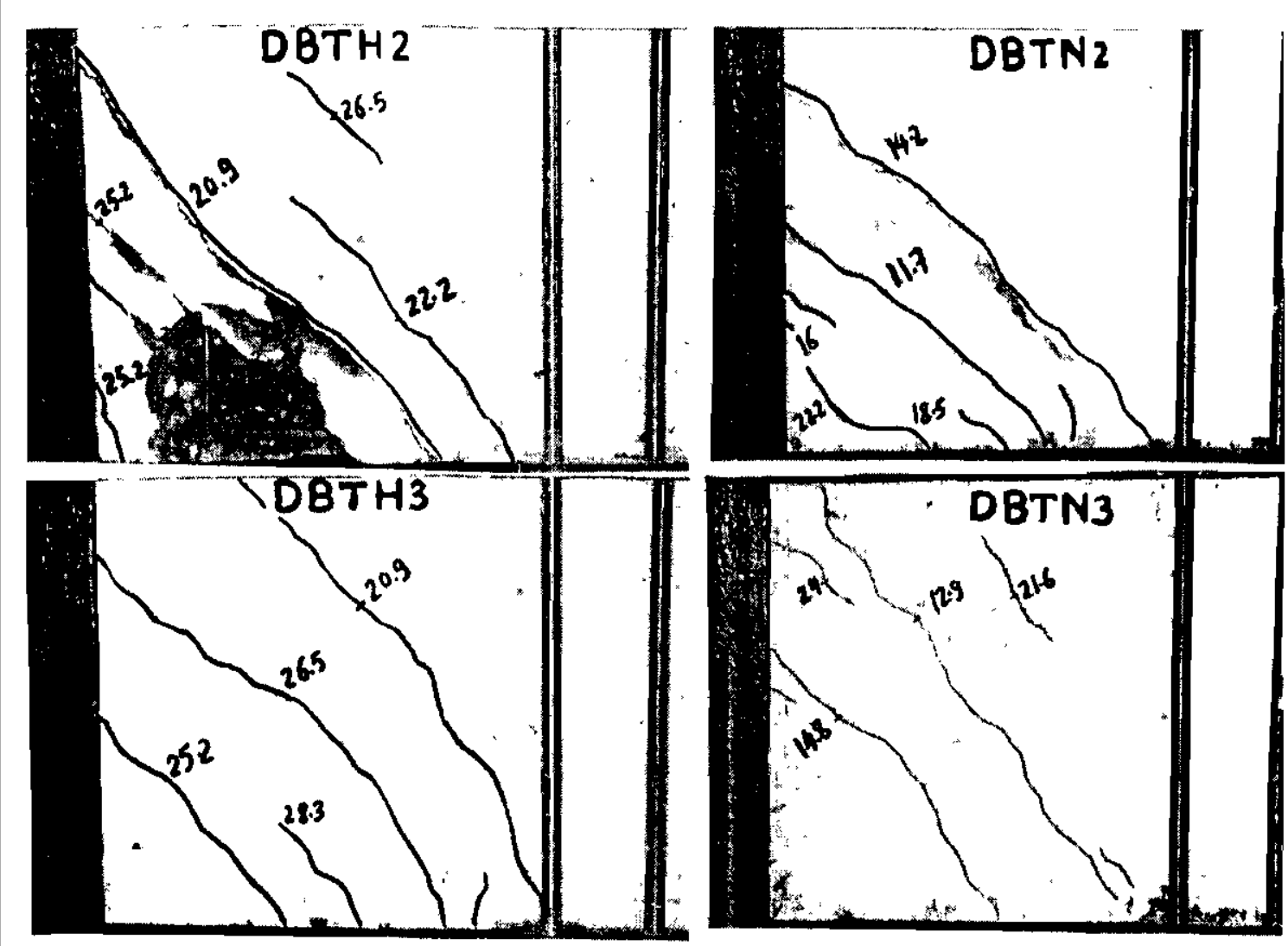

Fig. (6): Photographs of the crack patterns of some the tested NSC and HSC deep beams with $L / h=1.0$. 

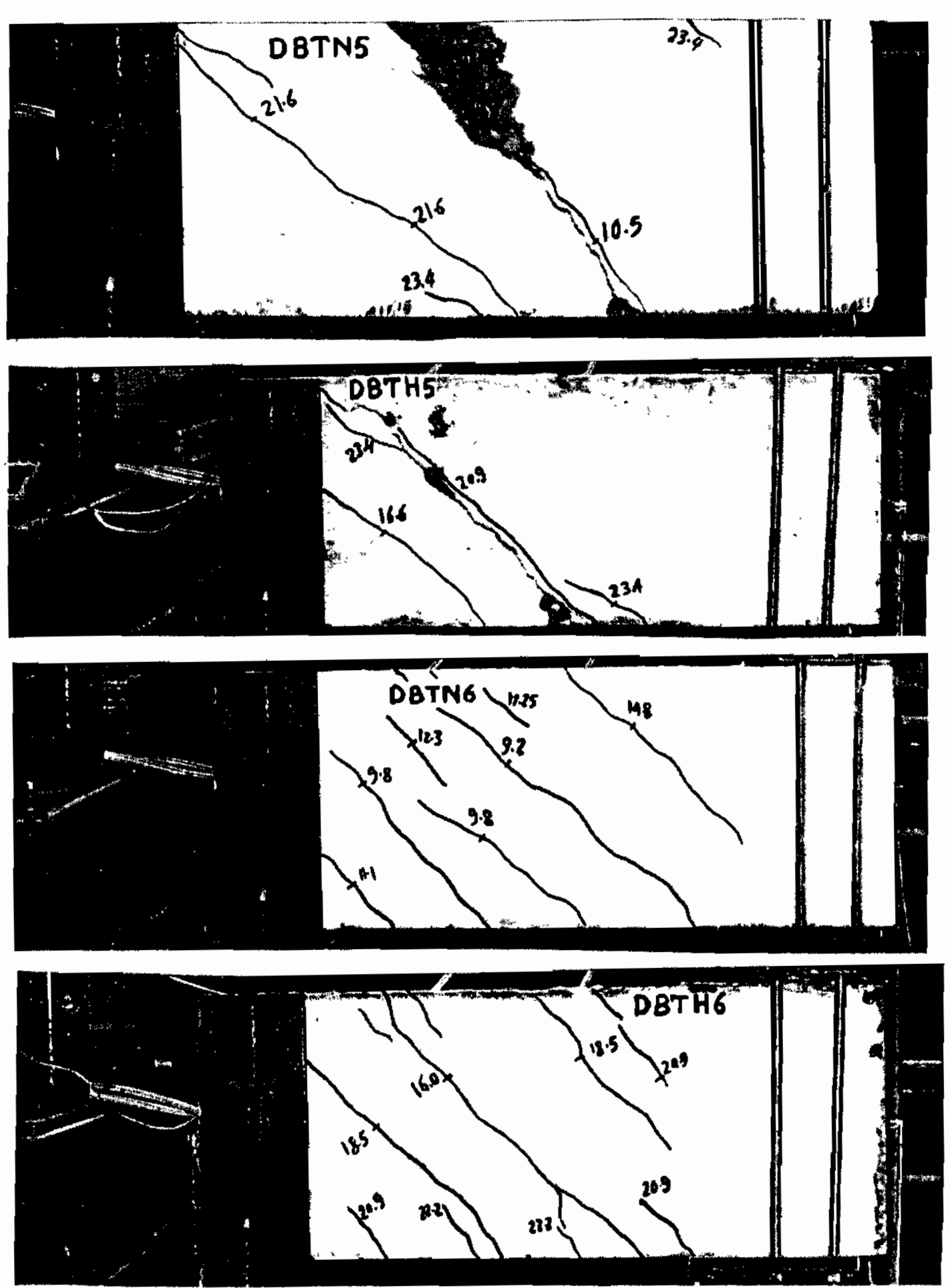

Fig. (7): Photographs of the crack patterns of the tested NSC and HSC deep beams with $L / h=2.0$. 


\subsection{Applied Torsional Moment- Twist Relationships}

The experimental torsional moment versus the angle of twist relationships for some of the tested HSC and NSC deep beams are shown in Fig. 8. Thesc curves are approximately linear up to cracking and thereafter become nonlinear with a large drop in the torsional stiffness (as represented by the slope of the curve). Comparing the recorded torsional momenttwist relationships for similar NSC and HSC beams showed that increasing the concretc strength reduces the angle of twist for different ratios of transverse and longitudinal reinforcement. Increasing the transverse reinforcement ratio did not have considerable effect on the applied torsional moment-angle twist relationships. In addition, the torsional postcracking stiffness increases as $f_{c}{ }^{\circ}$ increases for the same $L / h$ ratio as can be seen from Fig. $8 \mathrm{a}$ to $8 \mathrm{c}$. The effect of $L / h$ ratio on the torsional moment-twist relationships can be seen from Fig. 8d. Increasing the $L / h$ ratio from 1 to 3 , for the similar deep beams, reduces considerably the torsional postcracking stiffness as can be seen for beams DBTH2, DBTH5 and DBTH7.

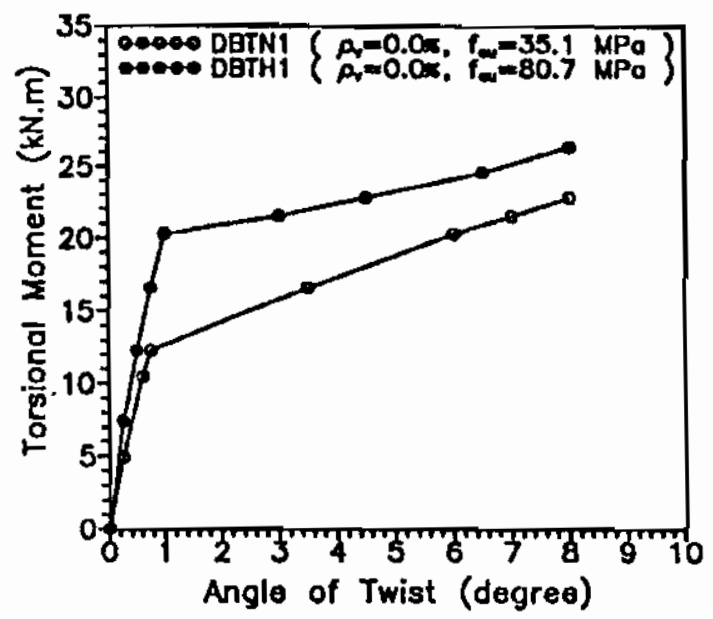

(a)

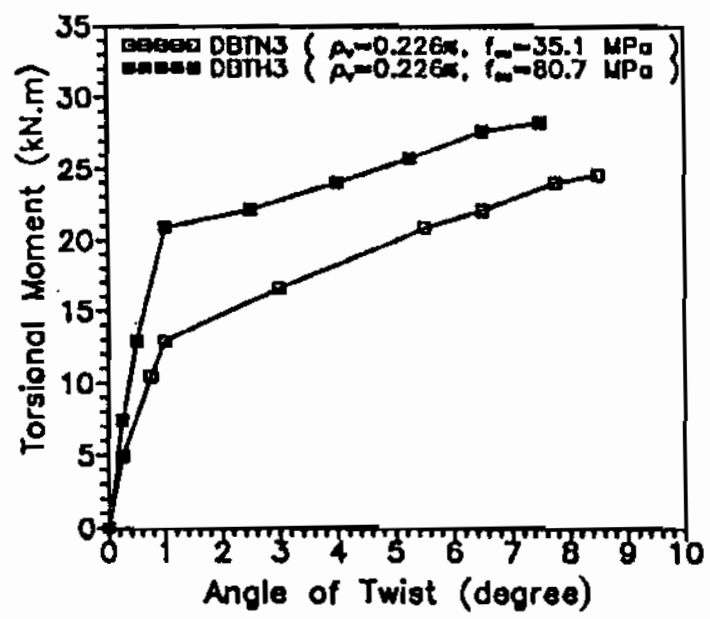

(c)

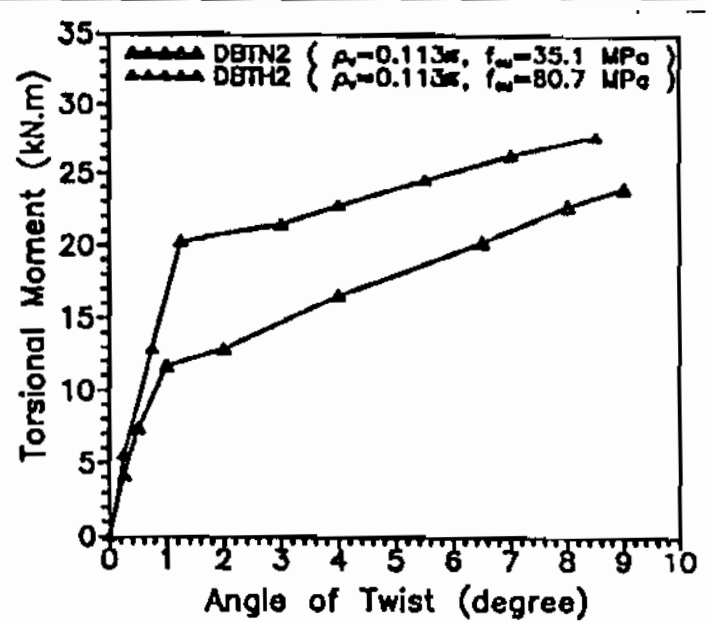

(b)

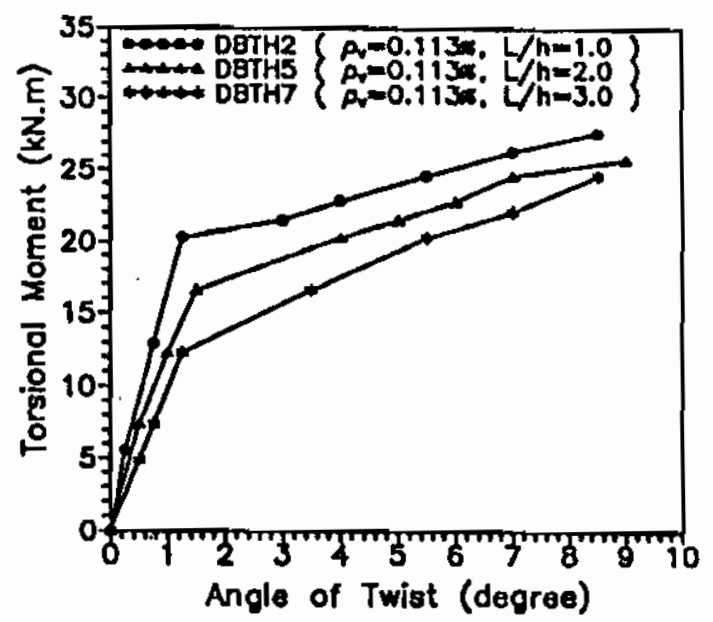

(d)

Fig. (8): Experimental torsional moment-angle of twist relationships for some of the tested deep beams. 


\subsection{Applied Torsional Moment- Crack Width Relationships}

A plot of the applied torsional moment versus the maximum crack width for the tested NSC and HSC deep beams are shown in Fig. 9. In general, the spiral torsional cracks were relatively wide (about $0.10 \mathrm{~mm}$ ) immediately after their formations. The cracks grew rapidly with increasing the applied torsional moments. For the same $L / h$ ratio, the development of the major spiral torsional crack of NSC deep beams was considerably faster than that of the similar HSC deep beams as can be seen from Fig. 9a. The effect of transverse reinforcement on the development of diagonal cracks of the tested NSC and HSC deep beams can be easily. noticed from the difference bctween deep beams with the same longitudinal reinforcement and different ratios of transverse reinforcement.
For deep beams tested at the same $L / h$ ratio in Fig. 9a, it can be seen that the development of the major spiral torsional crack in deep beam DBTH2 with $s$ equals to $200 \mathrm{~mm}$ ( $\rho_{v} \%=0.113$ ), was faster than that of the similar deep beam BTH3 but with $s$ equals to $100 \mathrm{~mm} \mathrm{(} \rho_{v} \%=$ 0.226 ). Increasing the comer longitudinal reinforeement ratio or the addition of skin bars for the NSC and HSC deep beams did not have observed effect on the progress of the spiral torsional cracks. For the tested HSC and NSC deep beams with the same longitudinal and web reinforcement but with different $L / h$ ratio ( $L / h=1,2$ and 3), it can be seen from Fig. $9 \mathrm{~b}$ that, the lower the $L / h$ ratio the slower the spiral crack development.

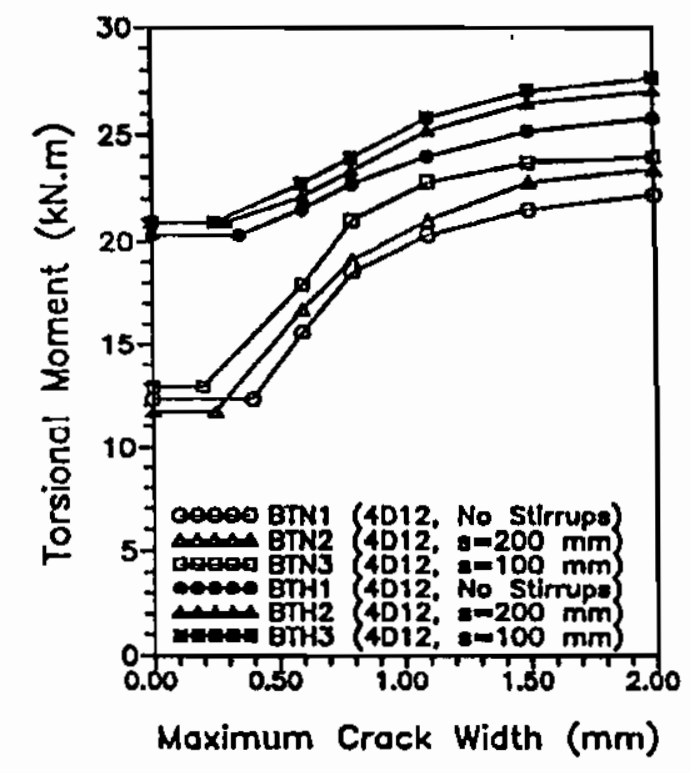

(a)

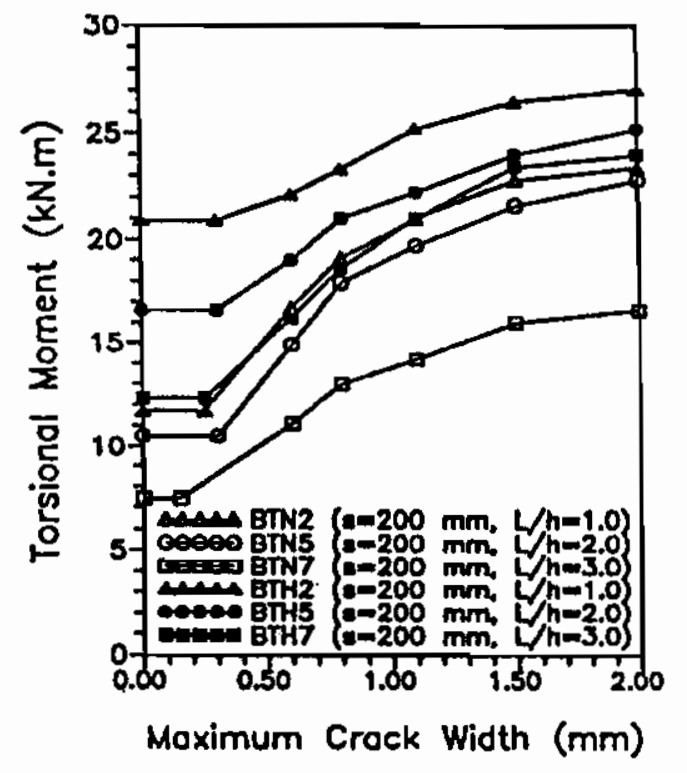

(b)

Fig. (9): Experimental torsional moment-maximum crack width relationships For some of the tested deep beams. 


\section{COMPARISON OF TEST RESULTS WITH THE TORSION PROVISIONS}

The equation used by the NZS 3101-95, $\mathrm{ACl}$ 318-02 building code and ECCS-2001 for calculating the cracking torsional strength for reinforced concrete deep beams (Eq. 1) have been used to predict the cracking torsional strength $T_{\text {crPRE }}$ of the tested beams ( 7 NSC deep beams +7 HSC deep beams). A comparison between the recorded experimental cracking strength $T_{\text {crEYP }}$ and the predicted values $T_{\text {crPRE }}$ are given in Table 2. The mean value of the ratio $T_{C r E X P}$ to $T_{C r P R E}$ for NSC and HSC deep beams is 2.21 and 2.38, respectively, with a coefficient of variation of 0.170 and 0.167 , respectively. This shows that the equation used by the three mentioned codes underestimates the cracking strength of NSC and HSC deep beams subjected to pure torsion. A little modification to liquation 1 can be proposed by changing the value 0.33 to be 0.40 . The calculated values of the cracking torsional strength of the tested deep beams using the proposed equation $T_{c r P R O}$ is given in Table 2 . The mean value of the ratio ( $\left.T_{\text {crEXP }} / T_{\text {crPRO }}\right)$ for NSC and HSC deep beams is 1.83 and 1.96 , respectively, with a coefficient of variation of 0.169 and 0.168 , respectively.

The torsion design methods for reinforced concrete beams according to the provisions of the ACI 318-02 building code, NZS 3101-95, ECCS-2001 and EC-2 are used to predict the ultimate torsional strength of the NSC and HSC deep beams of this study depending on the ultimate concrete strength $T_{u c}$, ultimate strength of stirrups $T_{u t}$ and ultimate strength of longitudinal bars $T_{u l}$, respectively, as can be seen from Table 3 and Table 4. The maximum ultimate torsional moment predicted by the studied codes $T_{U M A X P}$ are also given in Table 3 and 4 . The calculated values of the angle $\theta$ between the concrete struts and the longitudinal axis of the beam (using Eq. 7) are also summarized in Table 3 . It can be seen that, although all the studied codes adopted the same thin-walled tube and truss model the calculated torsional strength for the tested NSC and HSC deep beams according to these codes differ markedly. Under-reinforced beam according to one code maybe overreinforced or partially over-reinforced according to another code. The great differences in the predicted values of the torsional moment strength of the tested NSC and HSC deep beams are due to the great differences in the values of the angle $\theta$ adopted by each code. According to NZS $3101-95$ and ECCS-2001 the angle $\theta$ is taken equal to $45 \mathrm{deg}$. According to the ACI 318-02 the angle $\theta$ is taken between $30 \mathrm{deg}$ and $60 \mathrm{deg}$, while according to the EC-2 the angle $\theta$ is taken between 21.8 and $68.2 \mathrm{deg}$. The $\mathrm{ACl} 318-02$ code allows also that $\theta$ can be taken equal $45 \mathrm{deg}$ for nonprestressed members. For this case, the provisions of ACI 318-02 will be greatly similar to that of ECCS-2001. The value of the angle $\theta$ considerably affects the predicted values of the ultimate torsional strength depending on the ultimate strength of stirrups and ultimate strength of longitudinal bars. It can be seen also from Tables 3 and 4 that, for the tested NSC and HSC deep beams, the equations used by the ACI 318-02, NZS 3101-95 and ECCS-2001 underestimate the ultimate torsional strength of the concrete $T_{u c}$, while the equations used by the EC-2 predict reasonably these values. This can be attributed to the relatively small limits put by the ACI 318-02 and ECCS-2001 on :he maximum torsional strength of concrete as can be seen from Equations 4 and I2. The NZS 3101-95 limited this value to be less than or equal to $0.2 f_{c}$ or $6 \mathrm{MPa}$. The limits of NZS 3101-95 are also very conservative when applied for NSC and HSC deep bcams. 
Table (3): Calculated torsional strength according to the ACI 318-02 code.

\begin{tabular}{|c|c|c|c|c|c|c|c|c|c|}
\hline \multirow[t]{2}{*}{ Beam } & \multirow{2}{*}{$\begin{array}{c}\theta \\
(\operatorname{deg}) \\
\text { Eq. } 6\end{array}$} & \multicolumn{4}{|c|}{$\begin{array}{c}\text { ACI } 318-02 \\
(\theta=30-60 \mathrm{deg})\end{array}$} & \multicolumn{4}{|c|}{$\begin{array}{l}\text { ACI } 318-02 \\
(\theta=45 \mathrm{deg})\end{array}$} \\
\hline & & $\begin{array}{c}T_{u c} \\
k N . m\end{array}$ & $\begin{array}{c}T_{u t} \\
k N . m\end{array}$ & $\begin{array}{c}T_{u l} \\
k N . m\end{array}$ & $\begin{array}{c}T_{u M A X P} \\
K N . m\end{array}$ & $\begin{array}{c}T_{u c} \\
k N . m\end{array}$ & $\begin{array}{c}T_{u t} \\
k N . m\end{array}$ & $\begin{array}{c}T_{u l} \\
k N . m\end{array}$ & $\begin{array}{c}T_{\text {uMAXP }} \\
K N . m\end{array}$ \\
\hline DBTN1 & - & 7.46 & - & 6.36 & 7.46 & 7.46 & - & 11.01 & 11.01 \\
\hline DBTN2 & 24.61 & 7.46 & 4.01 & 6.36 & 7.46 & 7.46 & 2.31 & 11.01 & 11.01 \\
\hline DBTN3 & 32.95 & 7.46 & 7.14 & 7.14 & 7.46 & 7.46 & 4.63 & 11.01 & 11.01 \\
\hline DBTN4 & 17.35 & 7.46 & 4.01 & 14.38 & 14.38 & 7.46 & 2.31 & 24.90 & 24.90 \\
\hline DBTN5 & 24.61 & 7.46 & 4.01 & 6.36 & 7.46 & 7.46 & 2.31 & 11.01 & 11.01 \\
\hline DBTN6 & 32.95 & 7.46 & 7.14 & 7.14 & 7.46 & 7.46 & 4.63 & 11.01 & 11.01 \\
\hline DBTN7 & 24.61 & 7.46 & 4.01 & 6.36 & 7.46 & 7.46 & 2.31 & 11.01 & 11.01 \\
\hline DBTHI & - & 11.61 & - & 6.36 & 11.61 & 11.61 & - & 11.01 & 11.61 \\
\hline DB'TH2 & 24.61 & 11.61 & 4.01 & 6.36 & 11.61 & 11.61 & 2.31 & 11.01 & 11.61 \\
\hline DBTH3 & 32.95 & 11.61 & 7.14 & 7.14 & 11.61 & 11.61 & 4.63 & 11.01 & 11.61 \\
\hline DBTH4 & 17.35 & 11.61 & 4.01 & 14.38 & 14.38 & 11.61 & 2.31 & 24.90 & 24.90 \\
\hline DBTH5 & 24.61 & 11.61 & 4.01 & 6.36 & 11.61 & 11.61 & 2.31 & 11.01 & 11.61 \\
\hline DBTH6 & 32.95 & 11.61 & 7.14 & 7.14 & 11.61 & 11.61 & 4.63 & 11.01 & 11.61 \\
\hline DBTH7 & 24.61 & 11.61 & 4.01 & 6.36 & 11.61 & 11.61 & 2.31 & 11.01 & 11.61 \\
\hline
\end{tabular}

Table (4): Calculated torsional strength according to three of the studied codes.

\begin{tabular}{|c|c|c|c|c|c|c|c|c|c|c|c|c|}
\hline & \multicolumn{4}{|c|}{ ECCS-2001 } & \multicolumn{4}{c|}{ NZS $3101-95$} & \multicolumn{4}{c|}{ EC-2 } \\
\cline { 2 - 12 } Beam & $\begin{array}{c}T_{u c} \\
k N . m\end{array}$ & $\begin{array}{c}T_{u t} \\
k N . m\end{array}$ & $\begin{array}{c}T_{u l} \\
k N . m\end{array}$ & $T_{u M A X P}$ & $T_{u c}$ & $T_{u t}$ & $T_{u l}$ & $T_{u M A X P}$ & $T_{u c}$ & $T_{u t}$ & $T_{u l}$ & $T_{u M A A X P}$ \\
& $k N . m$ & $k N . m$ & $k N . m$ & $k N . m$ & $k N . m$ \\
$k N . m$ & $k N . m$ & $k N . m$ \\
\hline DBTN1 & 6.46 & - & 9.57 & 9.57 & 6.63 & - & 10.52 & 10.52 & 6.87 & - & 4.41 & 6.87 \\
DBTN2 & 6.46 & 2.01 & 9.57 & 9.57 & 6.63 & 2.05 & 10.52 & 10.52 & 7.55 & 5.04 & 5.05 & 7.55 \\
DBTN3 & 6.46 & 4.02 & 9.57 & 9.57 & 6.63 & 4.10 & 10.52 & 10.52 & 9.09 & 7.14 & 7.14 & 9.09 \\
DBTN4 & 6.46 & 2.01 & 21.65 & 21.65 & 6.63 & 2.05 & 22.55 & 22.55 & 6.87 & 5.78 & 9.96 & 9.96 \\
DBTN5 & 6.46 & 2.01 & 9.57 & 9.57 & 6.63 & 2.05 & 10.52 & 10.52 & 7.55 & 5.04 & 5.05 & 7.55 \\
DBTN6 & 6.46 & 4.02 & 9.57 & 9.57 & 6.63 & 4.10 & 10.52 & 10.52 & 9.09 & 7.14 & 7.14 & 9.09 \\
DBTN7 & 6.46 & 2.01 & 9.57 & 9.57 & 6.63 & 2.05 & 10.52 & 10.52 & 6.87 & 5.04 & 5.05 & 6.87 \\
\hline DBTH1 & 10.71 & - & 9.57 & 10.71 & 6.76 & - & 10.52 & 10.52 & 13.54 & - & 4.41 & 13.54 \\
DBTH2 & 10.71 & 2.01 & 9.57 & 10.71 & 6.76 & 2.05 & 10.52 & 10.52 & 14.89 & 5.04 & 5.05 & 14.89 \\
DBTH3 & 10.71 & 4.02 & 9.57 & 10.71 & 6.76 & 4.10 & 10.52 & 10.52 & 17.92 & 7.14 & 7.14 & 17.92 \\
DBTH4 & 10.71 & 2.01 & 21.65 & 21.65 & 6.76 & 2.05 & 22.55 & 22.55 & 13.54 & 5.78 & 9.96 & 13.54 \\
DBTH5 & 10.71 & 2.01 & 9.57 & 10.71 & 6.76 & 2.05 & 10.52 & 10.52 & 14.89 & 5.04 & 5.05 & 14.89 \\
DBTH6 & 10.71 & 4.02 & 9.57 & 10.71 & 6.76 & 4.10 & 10.52 & 10.52 & 17.92 & 7.14 & 7.14 & 17.92 \\
DBTH7 & 10.71 & 2.01 & 9.57 & 10.71 & 6.76 & 2.05 & 10.52 & 10.52 & 14.89 & 5.04 & 5.05 & 14.89 \\
\hline
\end{tabular}


Table (5): Comparison between the experimental results and the maximum torsional strength predicted by the studied codes.

\begin{tabular}{|c|c|c|c|c|c|c|}
\hline Beam & $\begin{array}{l}T_{u E X P} \\
k N . m\end{array}$ & $\begin{array}{c}\text { ACI } 318-02 \\
(\theta=30-60 \mathrm{deg}) \\
\frac{T_{u E X P}}{T_{u M A X P}}\end{array}$ & $\begin{array}{c}\text { ACI } 318-02 \\
(O=45 \mathrm{deg}) \\
\frac{T_{u E X P}}{T_{u M A X P}}\end{array}$ & $\begin{array}{c}\text { ECCS-2001 } \\
\frac{T_{u E X P}}{T_{u M A X P}}\end{array}$ & $\begin{array}{l}\text { NZS 3101-95 } \\
\frac{T_{u E X P}}{T_{u M A X P}}\end{array}$ & $\begin{array}{l}\mathrm{EC-2} \\
\frac{T_{u E X P}}{T_{u M A X P}}\end{array}$ \\
\hline DBTN & 22.80 & 3.06 & $2 . \overline{07}$ & 2.38 & 2.17 & 3.31 \\
\hline DBTN2 & 24.00 & 3.22 & 2.18 & 2.51 & 2.28 & 3.18 \\
\hline DBTN3 & 24.60 & 3.30 & 2.23 & 2.57 & 2.34 & 2.34 \\
\hline DBTN4 & 25.80 & 1.79 & 1.04 & 1.19 & 1.14 & 2.59 \\
\hline DBTN5 & 23.40 & 3.14 & 2.13 & 2.13 & 2.22 & 3.10 \\
\hline DBTN6 & 24.00 & 3.22 & 2.18 & 2.45 & 2.28 & 2.64 \\
\hline DBTN7 & 17.20 & 2.31 & 1.56 & 1.80 & 1.63 & 2.50 \\
\hline DBTHI & 26.40 & 2.27 & 2.27 & 2.46 & 2.51 & 1.95 \\
\hline DBTH2 & 27.70 & 2.39 & 2.39 & 2.59 & 2.63 & 1.86 \\
\hline DBTH3 & 28.30 & 2.44 & 2.44 & 2.64 & 2.69 & 1.58 \\
\hline DBTH4 & 30.10 & 2.09 & 1.21 & 1.39 & 1.33 & 2.22 \\
\hline DBTH5 & 25.80 & 2.22 & 2.22 & 2.41 & 2.45 & 1.73 \\
\hline DBTH6 & 27.10 & 2.33 & 2.33 & 2.53 & 2.58 & 1.51 \\
\hline DBTH7 & 21.50 & 1.85 & 1.85 & 2.01 & 2.04 & 1.44 \\
\hline \multicolumn{2}{|c|}{$\begin{array}{c}\text { Mean / C.O.V } \\
\text { (NSC Deep Beams) }\end{array}$} & $2.86 / 0.084$ & $1.91 / 0.218$ & $2.20 / 0.218$ & $2.01 / 0.208$ & $2.81 / 0.125$ \\
\hline \multicolumn{2}{|c|}{$\begin{array}{c}\text { Mean / C.O.V } \\
\text { (HSC Deep Beams) }\end{array}$} & $2.23 / 0.188$ & $2.10 / 0.193$ & $2.29 / 0.181$ & $2.32 / 0.194$ & $1.76 / 0.145$ \\
\hline
\end{tabular}

As can be seen from Table 5, the predictions of the ultimate torsional strength using $\mathrm{ACI}$ 318-02 provisions are very conservative for the tested NSC and HSC deep beams. The mean of the ratio $\left(T_{u E X P} / T_{u M A X P}\right)$ for the tested NSC and HSC deep beams of the case of ACI 318-02 code is 2.86 and 2.23 , respectively, with a coefficient of variation of 0.188 and 0.084 , respectively. This showed that, the applications of the equations of this code for NSC deep beams is more conservative than that of HSC beams. Using a value of the angle $\theta$ equal $45 \mathrm{deg}$ by $\mathrm{ACI} 318-02$ code will lead to a Ievel of conservation for the tested NSC and HSC deep beams which is less than that when the angle $\theta$ is taken between 30 and $60 \mathrm{deg}$.

According to EC-2, the ratio ( $T_{u E X P}$ / $T_{\text {uMAXXP }}$ ) for the tested HSC deep beams is considerably less than that of the tested NSC deep beams. Using a value of the angle $\theta$ as recommended by this code leads to a maximum prcdicted value of the torsional moment which is based on the ultimate strength of the concrete $T_{u c}$ (for all the tested HSC deep beams and all the tested NSC deep beams except DBTN4). For the ECCS-2001, NZS 3101-95 and ACI 318-02 $(\theta=45)$ codes, the conservatism reduces considerably with increasing the amount of torsional longitudinal bars for the tested NSC and HSC deep beams (DBTN4 and DBTH4). This shows that, for these codes, using the torsional strength of the deep beams based on the strength of the longitudinal bars $r: a y$ lead to unconservative results, especially for NSC deep beams. Consequently, for design purposes, the design ultimate torsional monent should be kept less than the ultimate torsional strength based on the ultimate torsional concrete strength or the ultimate torsional strength of the stirrups. 


\section{CONCLUSIONS}

Based on the results of this study, the following can be concluded:

1. The overall behavior of HSC deep beams in torsion is generally similar to that of the NSC beams. Increasing the concrete compressive strength of the tested beams from $f_{c u}=35.1 \mathrm{MPa}$ to $80.7 \mathrm{MPa}$ increases considerably the cracking torsional strength (by about $33-88 \%$ ) and slightly the ultimate torsional strength (by about I5-25\%). The failure of HSC deep beams under pure torsion is similar to that of the NSC beams and mainly controlled by the strain in the longitudinal corner bars of the beam regardless of the amount of the stirrups.

2. The rcserve in the torsional strength of the HSC deep beams after cracking is considerably less than that of the similar NSC deep beams. The cracking torsional strength of the NSC and HSC deep beams is $38-54 \%$ and $57-77 \%$ of the measured ultimate torsional strength, respectively.

3. The tested span to total height ratio $(L / h)$ have considerable effect on the cracking and the ultimate torsional strength of NSC and HSC beams. Increasing the $L / h$ ratio from 1 to 3 reduced the cracking torsional strength of NSC and HSC deep beams by about $37 \%$ and $41 \%$, respectively, and the ultimate torsional strength by about $28 \%$ and $22 \%$, respectively.

4. Although all the four codes examined in this study adopted the same thin-walled tube model, the torsional design equations differ markedly. However, the design torsional strength equations of the four codes were safe and conservative when applied to NSC and HSC deep beams.

5. The predictions of the ultimate torsional strength of the deep beams according to the method of ACI 318-02 and using a value of the angle between the concrete struts and the longitudinal axis of the beam $\theta$ equal to 45 deg may give a conservative results less than that calculated using this angle between 30 and $60 \mathrm{deg}$.
6. The calculation of the ultimate torsion strength using the angle $\theta$ equal to $45 \mathrm{deg}$ and depending on the amount of the longitudinal bars according to ACI 318-02, NZS 3101-95 and ECCS-2001 may lead to unsafe results when applied to NSC and HSC deep beams.

\section{REFERENCES}

1. ACI Committee 363, "State-of-theArt Report on High-Strength Concrete ", ACI 363R-92, American Concrete Institute, Mich., 1992, 55 p.

2. ACI-ASCE Committee 326 (1962), “ Shear and Diagonal Tension," ACI Journal, Proceedings V. 59, No.1, pp. 1-30 and No. 2, 1962, pp. 277-334.

3. Standards Association of New Zealand, "Code of Practice for the Design of Concrete Structures (NZS 3101)," Part 1\& Part 2, Wellington, New Zealand, 1995.

4. Commission of the European Communities, " Eurocode No. 2: Design of Concrete Structures," Part 1: General Rules and Rules for Buildings, October, 1990.

5. ACI Committee 318, "Building Code Requirements for Reinforced Concrete and Commentary (ACI 318-02)," American Concrete Institute, 2002.

6. Ministry of Housing, Utilities and Urban Communities, “Egyptian Code for Design and Construction of Reinforced Concrete Structures (ECCS 203-2001)," Cairo, 2001.

7. Rahal, K. N., and Collins, M. P., “ Experimental Evaluation of ACI and AASHTO-LRFD Design Provisions for Combined Shear and Torsion," ACl Structural Journal, Vol. 100, No. 3, May-June 2003, pp. 277-282.

8. Ashour, A. A., Samman, T. A., and Radain, T. A., " Torsional Behavior of Reinforced High-Strength Concrete Deep Beams," ACI Structural Journal, Vol. 96, No. 6, 1999, pp. 1049-1058. 